\title{
Diagnóstico Ambiental a partir da Declividade, Erosividade, Erodibilidade e o Índice SAVI no Semiárido Piauiense: estudo de caso no município de Juazeiro do Piauí
}

\author{
Environmental Diagnosis from Declivity, Erosivity, Erodibility and the SAVI Index in \\ the Semi-Arid Region of Piauí: a case study in the city of Juazeiro do Piauí
}

\begin{abstract}
Diagnóstico Ambiental a partir de la Declividad, Erosividad, Erodibilidad y el Índice SAVI en el Semiárido Piauiense: estudio de caso en el municipio de Juazeiro do Piauí
\end{abstract}

Francílio de Amorim dos Santos ${ }^{1}$

\begin{abstract}
RESUMO: O estudo objetivou caracterizar os componentes ambientais e avaliar e realizar diagnóstico do estado do meio natural do município de Juazeiro do Piauí, a partir das variáveis biofísicas. O estudo empregou metodologia quantitativo-qualitativa e abordagem descritiva, com emprego do Diagnóstico Físico Conservacionista (DFC) e os programas computacionais USUAIS e QGIS. Desse modo, delineou-se o valor mínimo 6 para representar a melhor qualidade ambiental e o valor máximo 19 para o pior estado de conservação. A área estudada assenta-se sobre as formações geológicas sedimentares Cabeças $(78,2 \%)$ e Pimenteiras $(21,8 \%)$. O relevo apresenta altitudes que variam de 100 a 260 metros, predominando declividade plana a suave ondulada. O município é cortado pelos rios Poti e Parafuso e riacho Vertente e possui precipitações que oscilam entre 900 a 1.200 milímetros. Foram identificadas as seguintes subordens de solos: Latossolos Amarelos $(44,6 \%)$, Neossolos Litólicos $(39,2 \%)$, Neossolos Quartzarênicos $(13,1 \%)$ e Planossolos Háplicos $(3,1 \%)$. Esses solos são recobertos por estrato herbáceo a arbóreas mais encorpadas e cerrado rupestre. A fórmula descritiva do DFC apontou aumento da degradação ambiental no município de Juazeiro do Piauí da ordem de 1.067 unidades, considerando-se os anos de 1997 (11.448) e 2016 (12.515). Esse aumento possivelmente está associado à dinâmica das atividades econômicas e oscilações climáticas, que interferem no crescimento da cobertura vegetal. Logo, os dados devem ser tomados como elementos-chave para o planejamento territorial e a gestão e recuperação do quadro ambiental do município.
\end{abstract}

PALAVRAS-CHAVE: Área suscetível à desertificação. Norte do Piauí. Diagnóstico físico conservacionista. Degradação/conservação.

ABSTRACT: The objective of this study was to characterize the environmental components, to evaluate and to diagnose the state of the natural environment of the city of Juazeiro do Piauí, using biophysical variables. The study used quantitative-qualitative methodology and descriptive approach, using the Physical Conservationist Diagnosis (PCD) and the USUAIS and QGIS computational programs. Thus, the minimum value 6 was delineated to represent the best environmental quality and

\footnotetext{
${ }^{1}$ Instituto Federal de Educação, Ciência e Tecnologia do Piauí/Campus Piripiri. Avenida Rio dos Matos, s/n - Germano, Piripiri - PI, 74260-000. francilio.amorim@ifpi.edu.br.
} 
the maximum value 19 for the worst conservation status. The studied area is based on the sedimentary geological formations Cabeças (78.2\%) and Pimenteiras (21.8\%). The relief presents altitudes that vary from 100 to $260 \mathrm{~m}$, predominating flat slope to smooth undulating. The municipality is cut by the rivers Poti and Parafuso and stream Vertente and has precipitations that oscillate between 900 to $1.200 \mathrm{~mm}$. The following soil suborders were identified: Yellow Latosols (44.6\%), Lithoidal Neosols (39.2\%), Quartzarenic Neosols (13.1\%) and Planossolos Háplicos (3.1\%). These soils are covered by herbaceous stratum to more full-bodied trees and closed rock. The descriptive formula of the PCD indicated an increase of the environmental degradation in the municipality of Juazeiro do Piauí of the order of 1,067 units, considering the years of $1997(11,448)$ and 2016 $(12,515)$. This increase is possibly associated to the dynamics of economic activities and climatic oscillations, which interfere with the growth of the vegetation cover. Therefore, the data should be taken as key elements for territorial planning and the management and recovery of the environmental framework in the municipality.

KEYWORDS: Area Susceptible to Desertification. Northern Piauí. Physical Conservationist Diagnosis. Degradation/Conservation.

RESUMEN: El estudio tuvo como objetivo: caracterizar los componentes ambientales, evaluar y realizar diagnóstico del estado del medio natural del municipio de Juazeiro do Piauí, a partir de variables biofísicas. El estudio empleó metodología cuantitativa-cualitativa y enfoque descriptivo, con empleo del Diagnóstico Físico Conservacionista (DFC) y los programas computacionales USUAIS y QGIS. De este modo, delineó el valor mínimo 6 para representar la mejor calidad ambiental y el valor máximo 19 para el peor estado de conservación. El área estudiada se asienta sobre las formaciones geológicas sedimentarias Cabezas (78,2\%) y Pimenteiras (21,8\%). El relieve presenta altitudes que varían de 100 a $260 \mathrm{~m}$, predominando declividad plana a suave ondulada. El municipio es cortado por los ríos Poti y Tornillo y riacho Vertente y tiene precipitaciones que oscilan entre 900 a $1.200 \mathrm{~mm}$. Se identificaron los siguientes subordenes de suelos: Latossolos Amarillos (44,6\%), Neosolos Litólicos (39,2\%), Neosolos Quartzarénicos (13,1\%) y Planossolos Háplicos (3,1\%). Estos suelos son recubiertos por estrato herbáceo a arbóreas más encorpadas y cerrado rupestre. La fórmula descriptiva del DFC apunta un aumento de la degradación ambiental en el municipio de Juazeiro do Piauí del orden de 1.067 unidades, considerando los años 1997 (11.448) y 2016 (12.515). Este aumento posiblemente está asociado a la dinámica de las actividades económicas y las oscilaciones climáticas, que interfieren en el crecimiento de la cobertura vegetal. Por lo tanto, los datos deben ser tomados como elementos clave para la planificación territorial y la gestión y la recuperación del marco ambiental del municipio.

PALABRAS-CLAVE: Área susceptible a la desertificación. Norte de Piauí. Diagnóstico físico conservacionista. Degradación/conservación.

\section{INTRODUÇÃO}

O semiárido do Nordeste do Brasil (NEB) exibe paisagens distintas e de grande beleza cênica, fato que demanda o uso da abordagem geossistêmica como instrumento para o conhecimento e análise dos componentes ambientais de forma integrada. Nesse sentido, gera-se a possibilidade de construção de um banco de dados de modo a subsidiar o planejamento e a gestão ambiental. Nessa perspectiva, os estudos desenvolvidos em áreas 
semiáridas são de grande relevância, principalmente naquelas suscetíveis ao processo de desertificação.

Deve-se destacar que a paisagem do NEB é marcada por distintas características, que configuram inúmeras possibilidades para estudos ambientais. Desse modo, citam-se os componentes climáticos como um dos elementos que mais variam ao longo do polígono denominado semiárido, marcado, principalmente, por uma irregular distribuição das precipitações, altas temperaturas e significativo déficit hídrico fato que resulta numa paisagem peculiar, cujo relevo exibe formas oriundas de processos erosivos e sedimentação que geram em grande parte solos jovens. Esses constituem substrato para uma cobertura vegetal predominantemente adaptada às condições de semiaridez.

Cabe salientar a relevância de estudos voltados ao conhecimento dos componentes ambientais biofísicos e sua integração por meio de índices em áreas suscetíveis ao processo de desertificação, que são fruto da degradação ambiental em áreas áridas, semiáridas e subúmidas secas, resultado das variações climáticas e atividades humanas praticadas inadequadamente (CONFERÊNCIA DAS NAÇÕES UNIDAS SOBRE O MEIO AMBIENTE E DESENVOLVIMENTO, 1995).

O referido processo apresenta grande nível de complexidade e, como tal, demanda emprego de abordagem teórico-metodológica compatível. Desse modo, o estudo utilizou a abordagem geossistêmica, solidificada na Teoria Geral dos Sistemas (TGS) que Mendonça (1989) afirma ser bastante utilizada no âmbito das ciências naturais e, também, em estudos ligados à Geografia Física. Ressalta-se que a pesquisa apresentou metodologia quantitativo-qualitativa e abordagem descritiva, ao passo que os procedimentos técnicos constituem adaptação à proposta metodológica de Beltrame (1994), denominada de Diagnóstico Físico Conservacionista (DFC), que demandou a obtenção de arquivos cartográficos e seu respectivo manuseio via pacote de programas USUAIS e QGIS, versão 2.14 .

Enfatiza-se, portanto, a relevância do desenvolvimento de estudos no contexto do semiárido do NEB, particularmente no que diz respeito ao município de Juazeiro do Piauí, recorte territorial desta pesquisa, justificados pela demanda por conhecimento integrado acerca dos componentes biofísicos e possibilidade de avaliação do processo de desertificação. Desse modo, o estudo teve como objetivo caracterizar os componentes ambientais e avaliar e realizar diagnóstico do estado do meio natural do município de Juazeiro do Piauí, a partir das seguintes variáveis biofísicas: Declividade média $(D m)$, Erosividade das chuvas $(R)$, Erodibilidade dos solos $(k)$ e o Índice de vegetação ajustado ao solo $(S A V I)$. 
Diagnóstico Ambiental a partir da Declividade, Erosividade, Erodibilidade e o Índice SAVI no...

\section{ÁREA EM ESTUDO}

A pesquisa foi executada tomando-se como recorte territorial o município de Juazeiro do Piauí, que se localiza na Mesorregião Centro-Norte Piauiense e Microrregião de Campo Maior. Esse município apresenta uma área de 827,2 quilômetros quadrados, mais precisamente nas coordenadas geográficas 0510'19"S e 41ำ4'10"O; sua sede municipal situa-se a 158 quilômetros de Teresina, capital do estado do Piauí, tendo os seguintes limites: ao norte com Sigefredo Pacheco e Milton Brandão, ao sul com Castelo do Piauí e Buriti dos Montes, a leste com Buriti dos Montes, a oeste Castelo do Piauí e Sigefredo Pacheco (Figura 1) (AGUIAR; GOMES, 2004).

Figura 1 - Localização do município de Juazeiro do Piauí, estado do Piauí

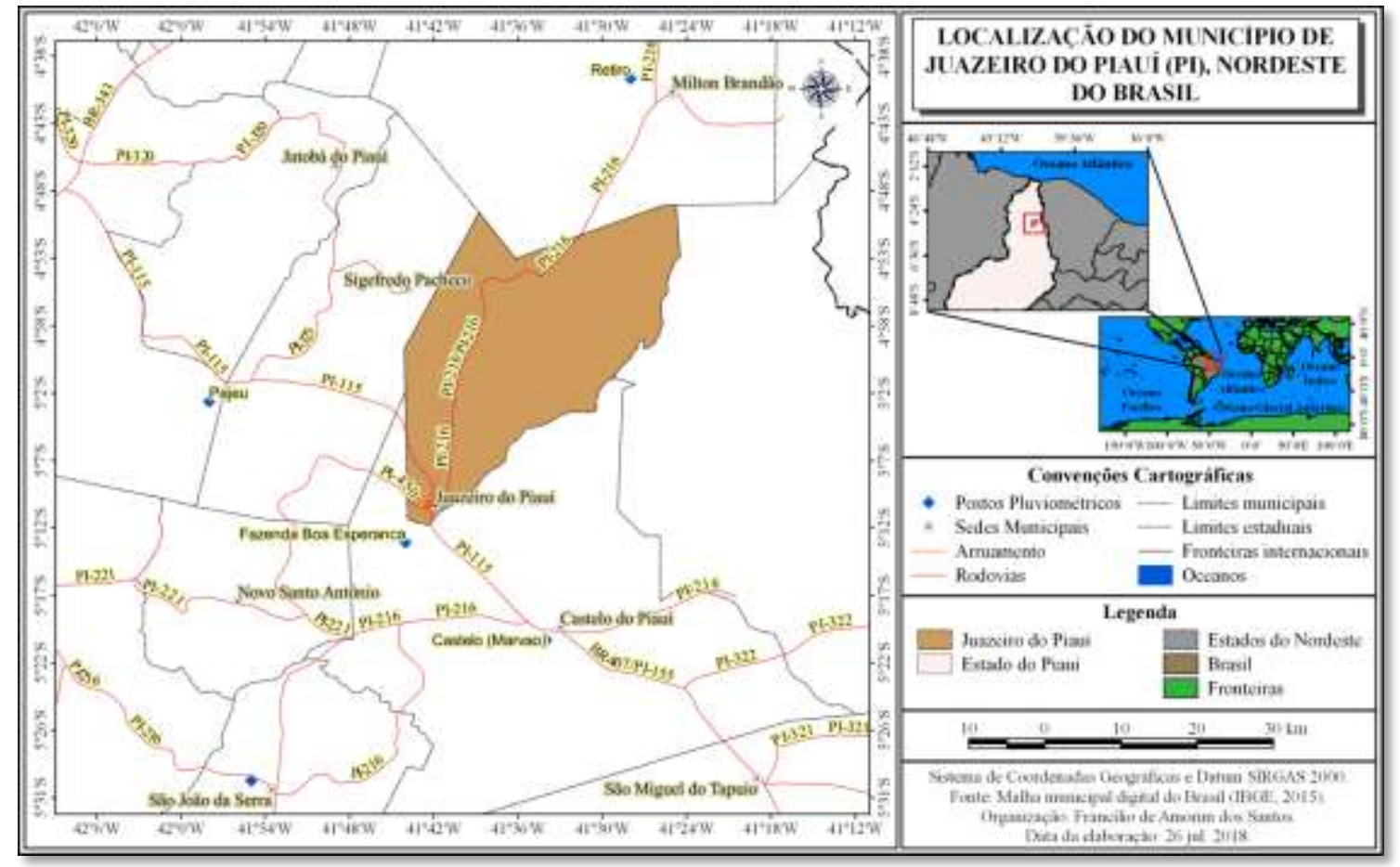

Fonte: IBGE (2015).

O município está assentado sobre as seguintes formações geológicas de natureza sedimentar, que datam da Era Paleozóica: Formação Cabeças, constituída por arenitos e siltito, que compreende $78,2 \%$ da área; Formação Pimenteiras, composta por arenitos vermelhos friáveis, siltitos e folhelhos, que se estende por $21,8 \%$ da área (BRASIL, 1973, 2006). Por sua vez, o relevo apresenta altitudes que variam de 100 a 260 metros, predominando cotas altimétricas de 180 metros a 260 metros, em 58,3\% do município, e declividade plana a suave ondulada em $81,4 \%$.

A área em estudo é cortada pelo rio Poti e Parafuso e riacho Vertente. Destaca-se que em $75 \%$ do município ocorrem precipitações que variam de 900 a 1.200 milímetros, 
conforme atestam os dados dos quatro postos pluviométricos da (ANA) Agência Nacional de Águas (2017), utilizados no estudo. Ocorrem quatro subordens de solos (INFRAESTRUTURA NACIONAL DE DADOS ESPECIAIS, 2014), a saber: Latossolos Amarelos (44,6\%); Neossolos Litólicos (39,2\%); Neossolos Quartzarênicos (13,1\%); e Planossolos Háplicos (3,1\%). Esses solos constituem substrato para o desenvolvimento de vegetação de diversas fisionomias e estágios de conservação e regeneração, apresentando estrato herbáceo a arbóreo mais encorpado, além da presença de cerrado rupestre, que se situa sobre os afloramentos rochosos e entre as linhas de drenagem temporárias (ALBINO, 2005).

\section{PROCEDIMENTOS METODOLÓGICOS}

A pesquisa apresentou natureza descritiva, e se voltou para o estudo das características ambientais com vistas à realização de diagnóstico do meio natural do município de Juazeiro do Piauí, a partir de algumas variáveis biofísicas. De acordo com Gil (2002), esse tipo de pesquisa prioriza a descrição de características ligadas à determinada população ou estabelecimento de relações entre variáveis. Nessa perspectiva, para alcançar os objetivos enumerados foram elencadas quatro variáveis biofísicas, detalhadas aqui.

\section{Declividade Média (Dm)}

Inicialmente, realizou-se aquisição de arquivo matricial ligado ao Modelo Digital de Elevação (MDE) da missão Shuttle Radar Topographic Mission (SRTM), obtido por meio do banco de dados do Serviço Geológico dos Estados Unidos (UNITED STATES GEOLOGICAL SERVICE, 2017b). Por sua vez, para delimitação das classes de declividade do relevo considerou-se a proposta metodológica da Empresa Brasileira de Agropecuária (EMBRAPA, 2009), a saber: 0 a 3\% (plano/peso 1); 3 a 8\% (suave ondulado/peso 2); 8 a $20 \%$ (ondulado/peso 3); 20 a 45\% (forte ondulado/peso 4).

\section{Erosividade das Chuvas $(R)$}

No que diz respeito à Erosividade das chuvas $(R)$ foi preciso, inicialmente, adquirir dados de quatro postos pluviométricos (Figura 1), para a série anual de 1963 a 2001, junto ao Sistema de Informações Hidrológicas (HidroWEB) da Agência Nacional de Águas (2017). Por sua vez, os procedimentos para correção das falhas da referida série foram efetuados por meio da técnica da ponderação regional proposta por Tucci (1993) associada a rotinas pertencentes aos programas do pacote USUAIS (OLIVEIRA; SALES, 2016), bem como 
Diagnóstico Ambiental a partir da Declividade, Erosividade, Erodibilidade e o Índice SAVI no...

espacialização dos resultados por meio do programa QGIS, conforme apresentado na Figura 2.

Figura 2 - Rotinas executadas no pacote de programas USUAIS, para refinamento dos dados dos postos pluviométricos e construção da Erosividade das chuvas $(R)$

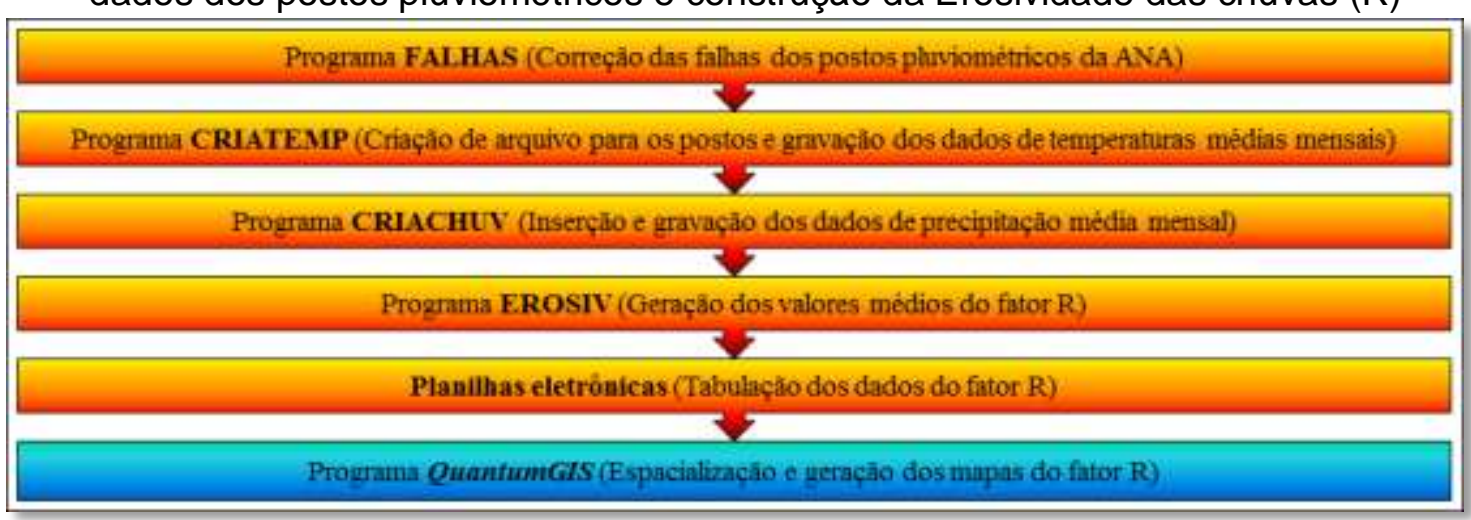

Fonte: Oliveira e Sales (2016).

A Erosividade foi estimada por meio do emprego da Equação 1, que se baseia no método estatístico da regressão linear considerando o índice médio mensal de erosão e o coeficiente de chuva (LOMBARDI NETO; MOLDENHAUER, 1992). A partir dos valores obtidos por meio dos dados pluviométricos, foram delimitadas cinco classes para o fator R: muito baixa (6.334,0 a $6.581,4$ MJ.mm/ha.h.ano/peso 1$)$; baixa $(6.581,4$ a $6.828,8$ MJ.mm/ha.h.ano/peso 2); média (6.828,8 a 7.076,2 MJ.mm/ha.h.ano/peso 3); alta (7.076,2 a 7.323,6 MJ.mm/ha.h.ano/peso 4); e muito alta (7.323,6 a 7.571,0 MJ.mm/ha.h.ano/peso 5). Ressalta-se que a unidade de medida utilizada diz respeito à quantidade de solo perdido em Mega Jaules (MJ) por milímetro por hectare por ano.

$$
E=67,355\left(r^{2} / P\right)^{0,85}
$$

Onde:

$\mathrm{E}=$ média mensal do índice de erosão (t/ha. $\mathrm{mm} / \mathrm{h})$;

$r=$ precipitação média mensal em $\mathrm{mm}$;

$\mathrm{P}=$ precipitação média anual em $\mathrm{mm}$.

\section{Erodibilidade dos Solos $(K)$}

Para análise desse parâmetro foi necessário adquirir arquivo vetorial dos solos da folha SB.24 - Jaguaribe, no banco de dados da Infraestrutura Nacional de Dados Espaciais (INFRAESTRUTURA NACIONAL DE DADOS ESPECIAIS, 2014). Desse modo, as classes delimitadas para o fator K consideraram a proposta metodológica de Crepani et al. (2001), a 
saber: muito baixa (Latossolo Amarelo/peso 1); baixa (Planossolo Háplico/peso 2); e muito alta (Neossolos Litólico e Quartzarênico/peso 5).

\section{Índice de Vegetação Ajustado ao Solo (SAVI)}

Inicialmente, foram adquiridas duas imagens dos satélites Landsat 5 TM e Landsat 8 OLI, junto ao site da (USGS) United States Geological Service (2017a), que possuíam órbita/ponto 218/64, resolução de 30 metros e as seguintes datas de passagem: 28/08/1997 e 01/08/2016. As imagens passaram por processos de conversão geométrica e no caso da imagem do satélite Landsat 8 aplicou-se procedimento para conversão radiométrica (16 para 8 bits) via ferramentas do QGIS. Em seguida, empregou-se a Equação 2 do SAVI, que considera os efeitos do solo exposto nas cenas estudadas, a partir do ajuste do Índice de vegetação por diferença normalizada (NDVI) quando a superfície não está totalmente recoberta por vegetação (BORATTO; GOMIDE, 2013).

$$
S A V I=\frac{(N I R-R)}{(N I R+R+L)} *(1+L)
$$

Onde:

L corresponde a uma constante chamada de fator de ajuste do índice SAVI, que nesse estudo assumiu o valor de 0,5 , aplicado à vegetação com densidade intermediária.

Realizado o refinamento das imagens, foram delimitadas cinco classes de fisionomia da cobertura vegetal: alta atividade fotossintética (0,7 a 0,9/peso 1); média atividade fotossintética ( 0,5 a $0,7 /$ peso 2$)$; baixa atividade fotossintética $(0,3$ a $0,5 /$ peso 3$)$; muito baixa atividade fotossintética ( 0,1 a $0,3 /$ peso 4$)$; e solo exposto ( 0 a $0,1 /$ peso 5 ).

\section{Fórmula Descritiva para Diagnóstico do Estado do Meio Natural}

O diagnóstico do estado do meio natural do município de Juazeiro do Piauí considerou a proposta metodológica de Beltrame (1994), a partir do emprego de quatro variáveis biofísicas, onde foram estabelecidos pesos para cada classe. Desse modo, a fórmula descritiva inicial e final e os procedimentos para sua obtenção consideram as Equações 3 a 7, conforme estão representados na Figura 3.

A metodologia empregou a média ponderada para obter a contribuição de cada parâmetro biofísico para a fórmula descritiva final, que foi calculada por meio da rotina MEDPOND, pertencente ao pacote de programas USUAIS (OLIVEIRA; SALES, 2016), que utiliza as unidades de risco como medida para avaliar o estado do meio natural. 
Diagnóstico Ambiental a partir da Declividade, Erosividade, Erodibilidade e o Índice SAVI no...

Figura 3 - Etapas para obtenção da fórmula descritiva do DFC

\begin{tabular}{|c|}
\hline $\mathbf{D F C}=\mathbf{D M}+\mathbf{R}+\mathbf{K}+\mathbf{S A V I}$ (Equação descritiva do DFC) \\
\hline 8 \\
\hline $\mathbf{y}=\mathbf{a}+\mathbf{b x}$ (Equaçăo de Regressâo inicial) \\
\hline 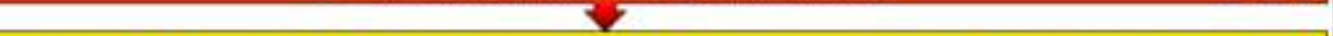 \\
\hline Se $x=4$, entào $y=0$, dai a equaçäo: $4 b+a=0$ (valores minimos das variáveis) \\
\hline 35 \\
\hline Se $x=19$, então $y=100$, dai a equação: $19 b+a=100$ (valores máximos das variáveis) [Eq 6] \\
\hline 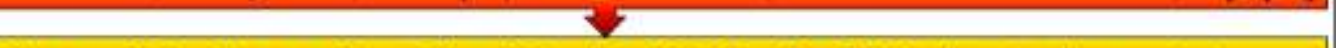 \\
\hline $9 b+a=100-(4 b+a=0) \rightarrow 19 b=100 \rightarrow b=100 / 19 \rightarrow b=5.26$ (subtraçăo de equaçōes) \\
\hline 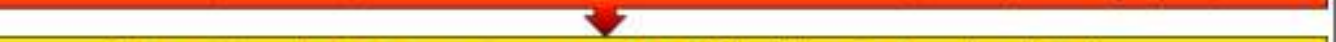 \\
\hline $4 \mathrm{~b}+\mathrm{a}=0 \rightarrow 4 \times 5.26+\mathrm{a}=0 \rightarrow \mathrm{a}=-\mathbf{2 1 . 0 4}$ (identificaço do valor de "a") \\
\hline$\gamma$ \\
\hline$y=21.04-5.26 x$ (Förmula de regressāo final) \\
\hline
\end{tabular}

Fonte: Beltrame (1994).

\section{RESULTADOS E DISCUSSÃO}

\section{Análise dos Indicadores Biofísicos}

A priori, cabe salientar que o relevo do município de Juazeiro do Piauí apresenta preponderância da classe plana a suave ondulada em $87,3 \%$ (722,1 quilômetros quadrados) de sua área, ao passo que o relevo ondulado e forte ondulado distribui-se por 11,4\% (94,3 quilômetros quadrados) e 1,3\% (10,8 quilômetros quadrados), respectivamente (Figura 4).

Figura 4 - Classes de declividade do relevo do município de Juazeiro do Piauí

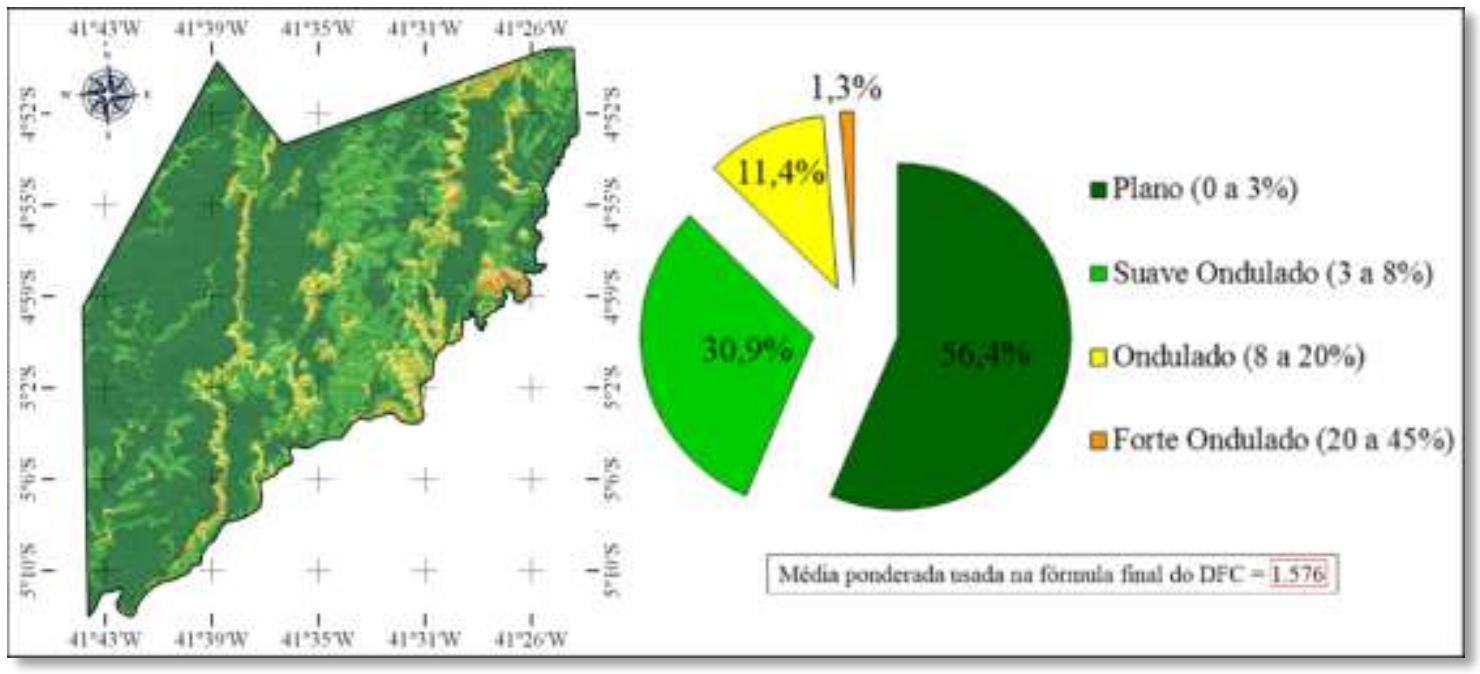

Fonte: United States Geological Service (2017b).

$\mathrm{Na}$ área estudada predomina alta a muito alta Erosividade das chuvas $(\mathrm{R})$, conforme está exposto na Figura 5, ocorrendo em 57,2\% (473,2 quilômetros quadrados), enquanto as classes de muito baixa, baixa e média Erosividade estendem-se por 0,3\% (2,5 quilômetros 
quadrados), 12,6\% (102,2 quilômetros quadrados) e 29,9\% (247,3 quilômetros quadrados), respectivamente.

Figura 5 - Classes de Erosividade das chuvas (R) do município de Juazeiro do Piauí

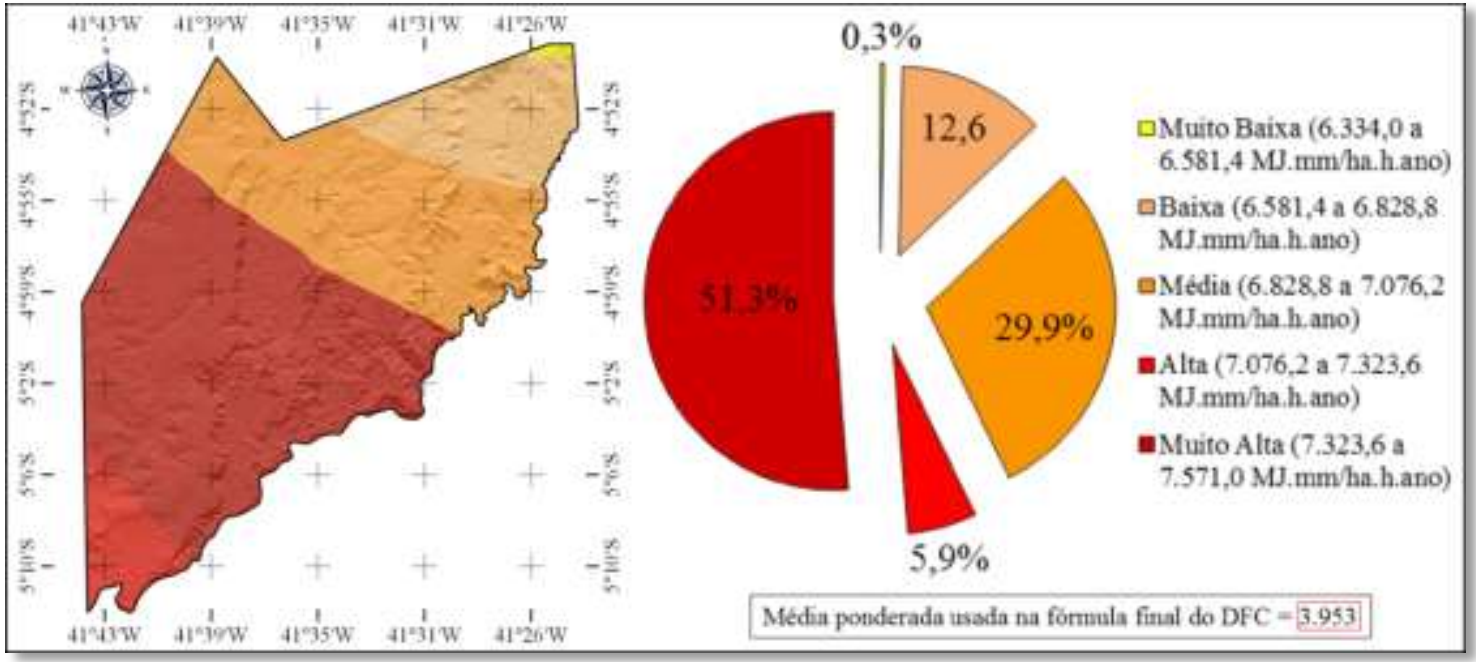

Fonte: Agência Nacional de Águas (2017).

Em Juazeiro do Piauí predomina a classe muito alta de Erodibilidade dos solos $(\mathrm{K})$, em $52,3 \%$ (432,7 quilômetros quadrados), conforme está representado na Figura 6, particularmente devido à presença de solos jovens (Neossolos Litólico e Quartzarênico). Por sua vez, as classes de muito baixa e de baixa Erodibilidade ocorrem em 44,6\% $(368,9$ quilômetros quadrados) e 3,1\% (25,6 quilômetros quadrados), respectivamente.

Figuras 6 - Classes de Erodibilidade dos solos (k) do município de Juazeiro do Piauí

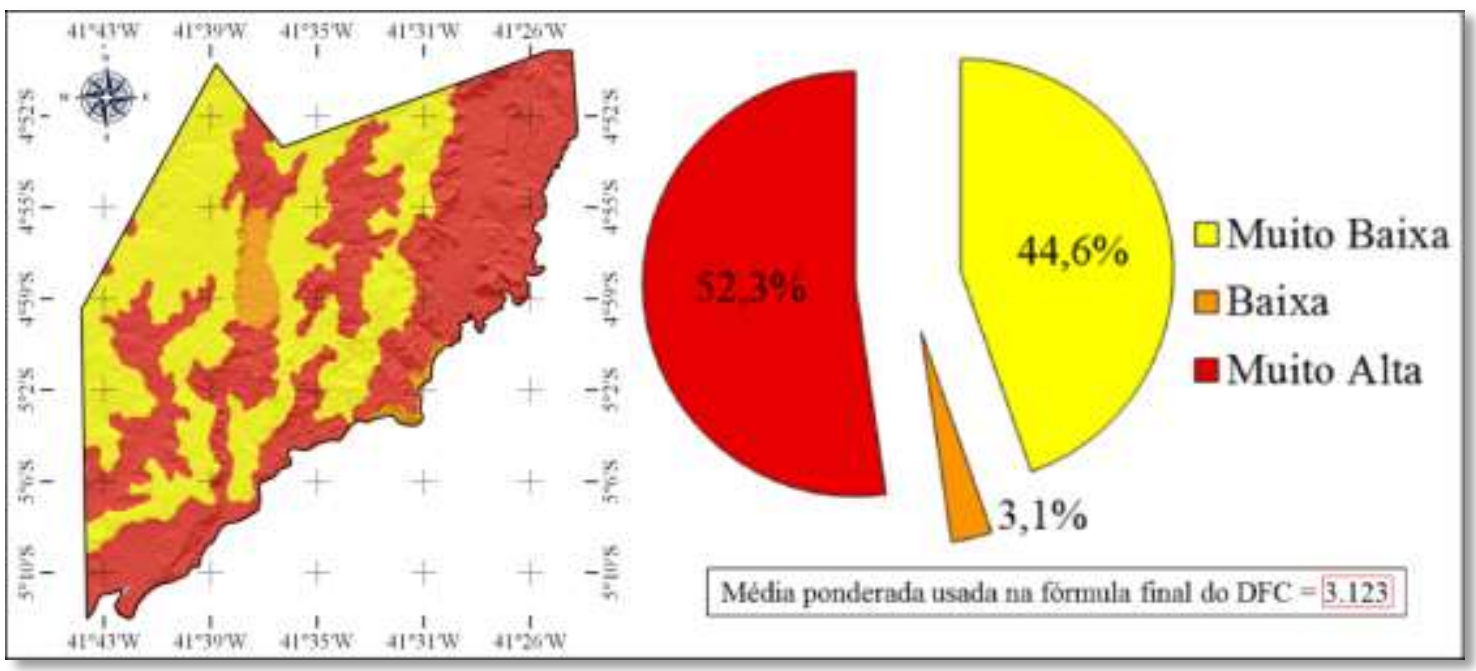

Fonte: Infraestrutura Nacional de Dados Especiais (2014).

No que diz respeito à cobertura vegetal, o SAVI apontou mudanças no padrão fisionômico (Figura 7). Ressalta-se que houve redução da classe de solo exposto, que 
passou de 1,7\% em 1997 para 0,6\% em 2016. Por sua vez, a classe de atividade fotossintética muito baixa sofreu considerável aumento, pois em 1997 distribuía-se por 25\% da área e passou a $85,1 \%$ em 2016. Deve-se destacar que essas mudanças são resultado da redução das classes de baixa e de média atividade fotossintética que em 1997 estendiam-se por $31,8 \%, 34,4 \%$ e passaram a $14,23 \%$, e $0,02 \%$, respectivamente. Diga-se, também, que a classe de alta atividade fotossintética que foi detectada em $7,2 \%$ da área, em 1997, não apareceu nos dados do ano de 2016.

Figuras 7 - Classes de fisionomia da cobertura vegetal do município de Juazeiro do Piauí, comparação entre os anos de 1997 e 2016

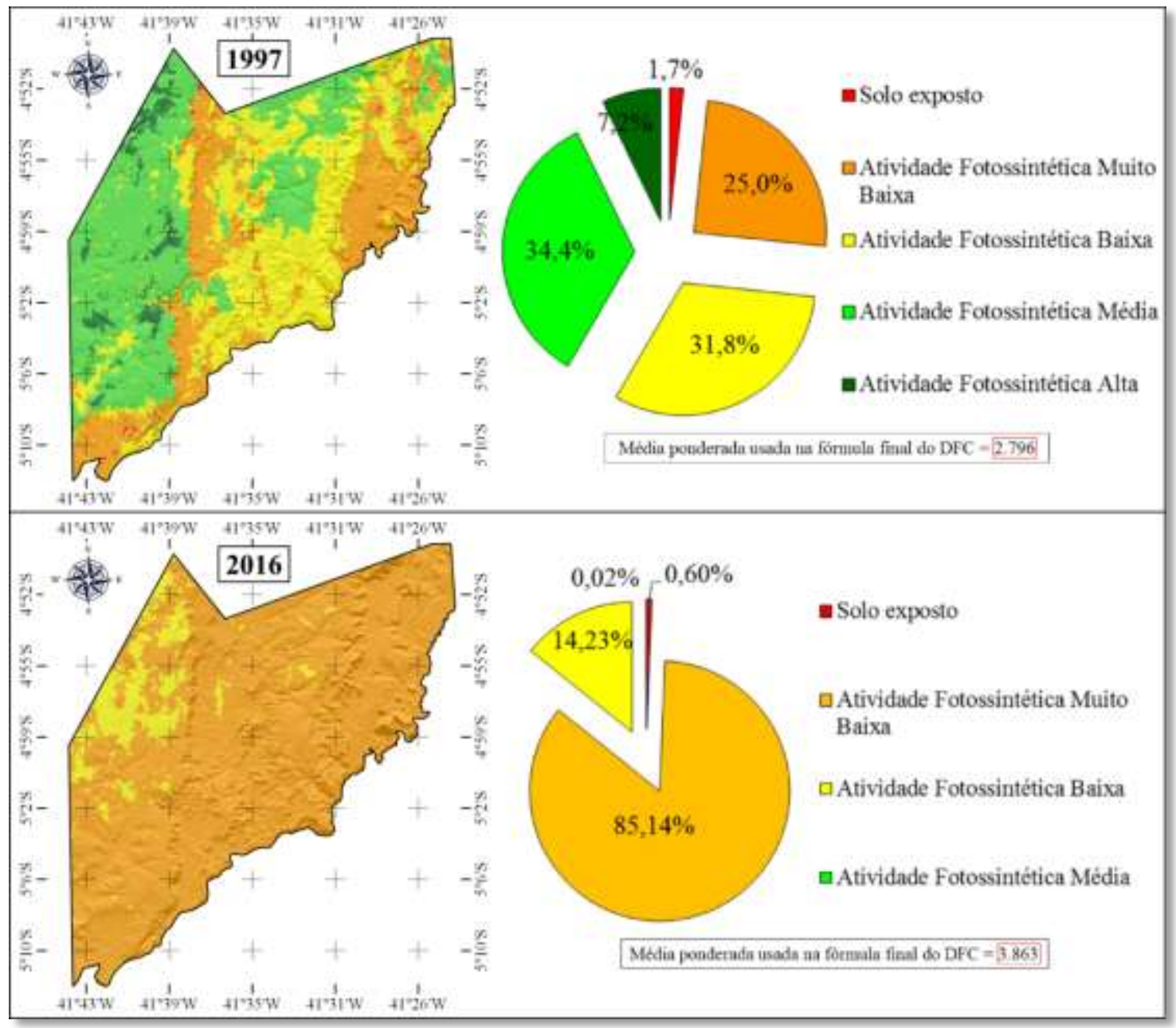

Fonte: United States Geological Service (2017a).

Deve-se ressaltar que essas mudanças, no padrão fisionômico da vegetação possivelmente são resultados da expansão das atividades humanas, a exemplo da agropecuária e supressão da cobertura vegetal para produção de lenha, associadas à redução dos totais pluviométricos na área estudada, conforme atestam o estudo realizado por Sales et al. (2015). 


\section{Avaliação da Fórmula Descritiva Final do Diagnóstico Físico Conservacionista}

A integração dos indicadores biofísicos por meio do somatório das médias ponderadas, elencados no DFC, permitiu avaliar o estado do meio natural no município de Juazeiro do Piauí, considerando os anos de 1997 e 2016 (Figura 8). Desse modo, por meio do DFC inferiu-se que ocorreu aumento da degradação ambiental na área estudada, visto que de 1997 (13.329 unidades) para 2016 (13.514 unidades) houve aumento da ordem de 0.185 unidades, fato esse que ocorreu devido às mudanças na fisionomia da cobertura vegetal.

Figura 8 - Somatório das variáveis analisados pelo DFC, para os anos de 1997 e 2016

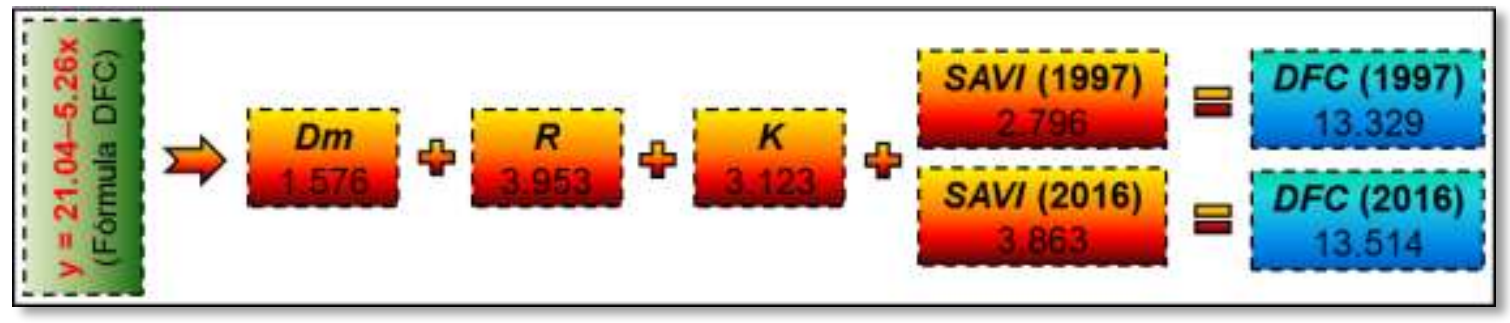

Elaborada: pelo autor (2018).

Destaca-se que as mudanças no padrão de fisionomia da cobertura vegetal atrelado às oscilações dos totais de precipitação média anual, possivelmente influenciaram na redução do porte e da biomassa da vegetação e, por consequência, interferiram no resultado do DFC, tendo esse indicado aumento da degradação ambiental no município estudado.

\section{CONSIDERAÇÕES FINAIS}

O uso da abordagem geossistêmica operacionalizada por meio do emprego de índice, particularmente o Diagnóstico Físico Conservacionista (DFC), para realização de diagnóstico do meio natural do município de Juazeiro do Piauí, apresentou grande relevância. Nesse sentido, pode-se afirmar que com as devidas adequações à proposta metodológica essa pode ser aplicada em outros recortes territoriais, mesmo aqueles fora do semiárido e não suscetíveis ao processo de desertificação.

Destaca-se, ainda, a relevância da integração das informações das quatro variáveis biofísicas (Dm, R, K, SAVI) que permitiu a realização de diagnóstico para o município, considerando os anos de 1997 e 2016. Nesse cenário, identificou-se no município estudado a predominância de: relevo plano a suave ondulado, que ocorre em $87,3 \%$; alta a muito alta Erosividade das chuvas (R), que se estende por $57,2 \%$; muito alta Erodibilidade dos solos 
Diagnóstico Ambiental a partir da Declividade, Erosividade, Erodibilidade e o Índice SAVI no...

(K), que se distribui por 52,3\%, e deve-se à ocorrência dos Neossolos Litólico e Quartzarênico; atividade fotossintética média em 1997 e atividade fotossintética muito baixa em 2016.

Por sua vez, o DFC indicou aumento da degradação ambiental, da ordem de 0.185 , quando considerados os anos de 1997 (13.514 unidades) e 2016 (13.329 unidades). Esse aumento pode estar associado às mudanças na fisionomia da cobertura vegetal, fruto da redução dos totais pluviométricos e dinâmica das atividades econômicas praticadas na área estudada.

Desse modo, os dados aqui apresentados configuram elementos essenciais à realização do melhor planejamento e gestão ambiental, bem como otimização das atividades econômicas no município de Juazeiro do Piauí.

\section{REFERÊNCIAS}

AGÊNCIA NACIONAL DE ÁGUAS - ANA. Hidro web: sistema de informações hidrológicas. Séries históricas: ano de 1985 a 2015. Brasília: ANA, [2017]. Disponível em: http://hidroweb.ana.gov.br/. Acesso em: 20 jul. 2017.

AGUIAR, R. B.; GOMES, J. R. C. (org.). Projeto cadastro de fontes de abastecimento por água subterrânea, estado do Piauí: diagnóstico do município de Castelo do Piauí. Fortaleza: Companhia de Pesquisa de Recursos Minerais, 2004.

ALBINO, R. S. Florística e fitossociologia da vegetação de cerrado rupestre de baixa altitude e perfil socioeconômico da atividade mineradora em Castelo do Piauí e Juazeiro do Piauí, Brasil. 2005. Dissertação (Mestrado em Desenvolvimento e Meio Ambiente) - Universidade Federal do Piauí, Teresina, 2005.

BELTRAME, A. V. Diagnóstico do meio físico de bacias hidrográficas: modelo e aplicação. Florianópolis: UFSC, 1994.

BORATTO, I. M. P.; GOMIDE, R. L. Aplicação dos índices de vegetação NDVI, SAVI e IAF na caracterização da cobertura vegetativa da região Norte de Minas Gerais. In: SIMPÓSIO BRASILEIRO DE SENSORIAMENTO REMOTO, 16., 2013, Foz do Iguaçu. Anais [...]. São José dos Campos: INPE, 2013. p. 7345-7352.

BRASIL. Ministério de Minas e Energia. Departamento Nacional de Produção Mineral. Projeto RADAM: levantamento dos recursos naturais. Folha SB.23-24: Teresina e Jaguaribe. Rio de Janeiro: IBGE, 1973. v. 2.

BRASIL. Ministério de Minas e Energia. Secretaria de Geologia, Mineração e Transformação Mineral. Mapa Geológico do Estado do Piauí. Versão 2. Brasília: MME, 2006.

CONFERÊNCIA DAS NAÇÕES UNIDAS SOBRE O MEIO AMBIENTE E DESENVOLVIMENTO, 1., 1992, Rio de Janeiro. Agenda 21. Brasília: Câmara dos Deputados, 1995.

CREPANI, E. et al. Sensoriamento remoto e geoprocessamento aplicados ao zoneamento ecológico-econômico e ao ordenamento territorial. São José dos Campos: INPE, 2001. 
EMBRAPA. Centro Nacional de Pesquisa de Solos. Sistema brasileiro de classificação de solos. Rio de Janeiro: EMBRAPA, 2009.

GIL, A. C. Como elaborar projetos de pesquisa. São Paulo: Atlas, 2002.

IBGE. Malha municipal digital do Brasil: situação em 2015. Rio de Janeiro: IBGE, 2015.

Disponível em: ftp://geoftp.ibge.gov.br/malhas_digitais/. Acesso em: 4 abr. 2016.

INFRAESTRUTURA NACIONAL DE DADOS ESPECIAIS - INDE. Mapa de solos da Folha SB.24: Jaguaribe. Escala 1:250.000. Brasília: INDE, [2014]. Disponível em: http://www.visualizador.inde.gov.br/. Acesso em: 27 nov. 2015.

LOMBARDI NETO, F.; MOLDENHAUER, W. C. Erosividade da chuva: sua distribuição e relação com perdas de solos em Campinas - SP. Bragantina, Campinas, v. 51, n. 2, p.1891996, 1992.

MENDONÇA, F. Geografia física: ciência humana? São Paulo: Contexto, 1989.

OLIVEIRA, J. G. B.; SALES, M. C. L. Usuais: programas para uso em análise ambiental. Revista Equador, Teresina, v. 5, n. 2, p. 36-60, jan./jun. 2016.

SALES, D. C. et al. Projeções de mudanças na precipitação e temperatura no nordeste brasileiro utilizando a técnica de Downscaling Dinâmico. Revista Brasileira de Meteorologia, São Paulo, v. 30, n. 4, p. 435-456, 2015.

TUCCI, C. E. M. Hidrologia: ciência e aplicação. Porto Alegre: UFRGS; São Paulo: USP, 1993.

UNITED STATES GEOLOGICAL SERVICE - USGS -. Earth explorer: digital elevation. SRTM 1 Arc-Second Global. Reston: USGS, 2017b. Disponível em http://earthexplorer.usgs.gov/. Acesso em: 3 jun. 2017.

UNITED STATES GEOLOGICAL SERVICE - USGS. Earth explorer. Reston: USGS, 2017a. Collection. Landsat Archive. Disponível em: http://earthexplorer.usgs.gov/. Acesso em: 3 jun. 2017.

Recebido: novembro de 2018.

Aceito: fevereiro de 2019. 